\title{
Factors influencing urban malaria: a comparative study of two communities in the Accra Metropolis
}

\author{
Brenyah RC ${ }^{1}$, Osakunor $\mathrm{DNM}^{2},{ }^{*}$ Ephraim RKD ${ }^{3}$
}

1. Department of Clinical Microbiology, School of Medical Sciences, College of Health Sciences, Kwame Nkrumah University of Science and Technology, Accra

2. Department of Molecular Medicine, School of Medical Sciences, College of Health Sciences, Kwame Nkrumah University of Science and Technology, Accra

3. Medical Laboratory Division, Department of Laboratory Technology, University of Cape Coast, Cape Coast

\begin{abstract}
Background: As urban centres in Ghana continue to grow, the scale and impact of urban malaria is increasing. Objective: To compare the prevalence of malaria in two communities and how this may be affected by knowledge, attitudes, socioeconomic status and preventive practices of residents in two communities within the Accra metropolis.

Methods: Giemsa-stained thick blood films were examined for malaria parasites in 400 people (200 each from townships with high and low urban status) from May to November 2009. Questionnaires were administered to determine and evaluate demographics of the participants. All participants lived within the two catchment areas, about $20 \mathrm{~km}$ apart.

Results: Average malaria prevalence among participants was $8.75 \%$. Prevalence in Kaneshie (12\%: $\mathrm{p}=0.032)$ was significantly higher compared to Airport West (5.5\%). Illiteracy rate (17.5\%), self-medication $(81.5 \%)$ and the use of coils $(21.0 \%)$ as a control mechanism was higher among residents of Kaneshie than Airport West. Most of the people (40\%) in Kaneshie did not use any form of malaria control method. Insecticide spray was the most preferred malaria control mechanism by the Airport West residents (60.5\%). Overall knowledge about malaria, employment status, housing conditions, level of overcrowding and the cost of treatment of malaria was better in Airport West than at Kaneshie.

Conclusion: Malaria prevalence and factors influencing its transmission differs within communities in the same urban area. It is therefore essential to develop control and prevention strategies based on the needs of specific communities.
\end{abstract}

Keyword: Malaria, prevalence, urbanization, demographics, insecticide spray, and insecticide treated nets. African Health Sciences 2013; 13(4): 992 - 998 http://dx.doi.org/10.4314/ahs.v13i4.19

\section{Introduction}

Malaria still presents a serious health problem in Ghana; it is hyper-endemic with a crude parasite rate ranging from $10-70 \%$ with Plasmodium falciparum being the major parasite ${ }^{1}$. It is a major cause of morbidity accounting for $40 \%$ of outpatient attendance with annual reported cases of 2.2 million between $1995-2001$, and over 10\% ending up on admission ${ }^{2}$.

Rapid urbanisation may have serious effects on malaria prevalence and thus control. This can

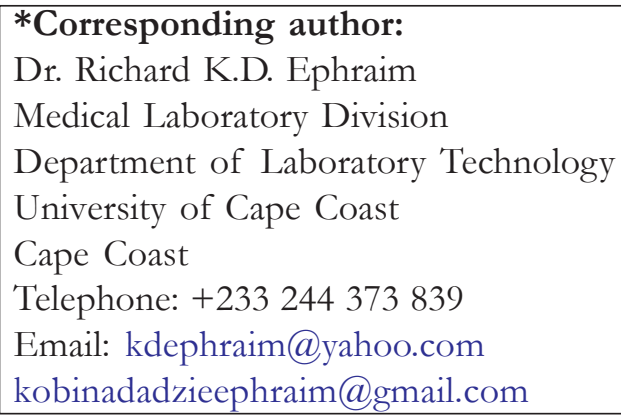

adjust the frequency and transmission modes of malaria, with huge implications for control ${ }^{3}$.

Until recently, urban development was generally believed to reduce the risk of vector breeding, and thus malaria transmission ${ }^{3}$. However, many countries, including Ghana are struggling to cope with the rapid rate of urban growth and the resultant increase in the prevalence of malaria in the urban $\operatorname{areas}^{3}$. The prevalence and undercurrents of malaria transmission has been changed as a result of rapid urbanization culminating in significant effects on malaria morbidity and mortality and its consequent implications on the control of malaria ${ }^{16}$.

Thus there is need to assess the malaria burden in urban areas together with information on personal, social and environmental factors to make way for more sound, area specific and effective control strategies. The study sought to identify factors, which may highlight differences in the prevalence of malaria, 
if any, and the effects of important behavioural, housing and vector control related parameters between two communities within an urban area in Accra, Ghana.

\section{Methods}

\section{Study sites and design}

This cross-sectional study was conducted in two communities, Kaneshie and Airport West residential area, both within the Accra metropolis in the Greater Accra region of Ghana. The region is located on the coordinates: $5^{\circ} 332003 \mathrm{~N} 0^{\circ} 122003 \mathrm{Wÿp} /$ $5.55^{\circ} \mathrm{N} 0.2^{\circ} \mathrm{W}$. It is the smallest of the 10 administrative regions of Ghana with its population accounting for 15.4 per cent of Ghana's total population ${ }^{4}$. Accra features a tropical savannah climate, with wet seasons from May to July and dry seasons from August to March ${ }^{4}$.

Kaneshie: The area has a large central market attracting people from various places to the locality. Urbanisation is fairly low to moderate with like standard of living. Housing system is predominantly compound with close proximity between houses. Though urban in nature rapid migration and brisk economic and commercial activities in the community has resulted in most drainage systems being chocked, rendering the area flood prone. The site and its surrounding provide quite good breeding grounds for mosquitoes.

Airport West residential area: General observation reveals that residents have a high standard of living. The housing system is predominantly residential, with proper spacing and well-constructed drains.

\section{Selection of study participants}

A total of 400 participants were recruited onto the study. 200 participants each were systematically selected using every $5^{\text {th }}$ patient in attendance, from the Lister Hospital, Airport West Residential area and Kaneshie Polyclinic, Kaneshie. Participants enrolled in the study, were resident in the catchment areas of interest and were of any age and gender. All participants on any form of anti-malaria therapy (prophylaxis or treatment) were excluded. Of the 400, 35 participants tested positive for malaria, 24 from Kaneshie and 11 from Airport West residential area. Informed consent was obtained from the participants and ethical clearance issued by the Committee for Human Research Publication and Ethics of the KNUST, School of Medical Sciences, Kumasi (CHRPE/SMS/KATH) and from the Lister Hospital and Kaneshie Polyclinic.
A questionnaire, prepared in the English language, was administered to each study participant. This was translated into the local languages where appropriate. The questionnaire sought to obtain information on socioeconomic factors, behavioral attitudes, housing and vector control-related parameters. Participants were made to give a brief description of their houses in terms of design, structure and other local environmental factors. This was then interpreted and categorised as excellent, very good, good and poor with reference to conditions decreasing vector lifespan and hindering malaria transmission.

\section{Sample collection and preparation}

About $0.5 \mathrm{ml}$ venous blood samples were collected from participants and dispensed into Ethylenediaminetetraacetic Acid (EDTA) tubes until processed. This was to enable repeated analysis of samples when the need arose. Thick blood films (TBFs) were prepared with approximately 20 il of well mixed blood, stained using the Giemsa staining technique (1:10 dilution, $\mathrm{pH} 8.0)$ and examined by light microscopy using a $\times 100$ magnifications ${ }^{5}$.

\section{Statistical analysis}

Continuous variables were expressed as Mean \pm SD. Student t-test was used to compare continuous variables and the Fisher's exact test for categorical variables. Confidence interval of $95 \%$ was employed. P-values less than 0.05 were considered significant. GraphPad Prism (Version 5) and Microsoft Excel 2008 software were used for analysis.

\section{Results \\ Prevalence and age distribution of study participants}

Four hundred (400) participants were enrolled in this study. Thirty five (35) (8.75\%) tested positive for plasmodium infection (malaria) after laboratory analysis. Of the 35, $24(12 \%)$ were from Kaneshie and 11 (5.5\%) from Airport West. This gave an average total prevalence of $8.75 \%$. Table 1 below shows the age distribution of all study participants. The number of participants aged 0-9 were more in Kaneshie (4.5\%: $\mathrm{p}=0.020)$ than in Airport West. 
Table 1: Age distribution of study participants

\begin{tabular}{lllll}
\hline & & \multicolumn{2}{c}{ Area of residence } & \\
\cline { 3 - 4 } $\begin{array}{l}\text { Age } \\
\text { (years) }\end{array}$ & $\begin{array}{l}\text { Total } \\
(\mathbf{n}=400)\end{array}$ & $\begin{array}{l}\text { Airport-West } \\
(\mathbf{n}=\mathbf{2 0 0})\end{array}$ & $\begin{array}{l}\text { Kaneshie } \\
(\mathbf{n}=\mathbf{2 0 0})\end{array}$ & \\
\hline $0-9$ & $10(2.5 \%)$ & $1(0.5 \%)$ & $9(4.5 \%)$ & 0.020 \\
$10-19$ & $37(9.3 \%)$ & $19(9.5 \%)$ & $18(9.0 \%)$ & 1.000 \\
$20-29$ & $150(37.5 \%)$ & $78(39.0 \%)$ & $72(36.0 \%)$ & 0.605 \\
$30-39$ & $111(27.8 \%)$ & $59(29.5 \%)$ & $52(26.0 \%)$ & 0.503 \\
$40-49$ & $65(16.3 \%)$ & $30(15.0 \%)$ & $35(17.5 \%)$ & 0.588 \\
$50-59$ & $14(3.5 \%)$ & $6(3.0 \%)$ & $8(4.0 \%)$ & 0.787 \\
$>59$ & $13(3.3 \%)$ & $7(3.5 \%)$ & $6(3.0 \%)$ & 1.000 \\
\hline
\end{tabular}

Clinical, demographic, housing and educational characteristics of study participants

Table 2 shows the general demographic characteristics of the study participants stratified by residency. The mean age of the study participants was $31.1 \pm 0.6$ and this was similar to the age found in the two separate areas sampled. Of the 400 participants interviewed from both sites, Plasmodium infection was significantly higher amongst Kaneshie residents $(12 \%: \mathrm{p}=0.032)$ than Airport West residents (5.5\%). All participants in Airport West had at least some level of education ( $0.0 \%$ illiteracy) whilst Kaneshie had a 17.5\% illiteracy rate $(\mathrm{p}<0.001)$.
Most of the inhabitants in Airport West generally did white-collar jobs $(42.5 \%$ : $\mathrm{p}<0.001)$ whilst most of those in Kaneshie were self-employed $(48.0 \%$ : $\mathrm{p}<0.001)$ and in various forms of labour, especially trading. Housing conditions existing in Airport West was better than in Kaneshie. The average number of people in homes within Kaneshie (5.2: $\mathrm{p}<0.001)$ was more than that at Airport West (3.7).

There was no significant difference in age, marital status, drug stock, the use of prophylactics and health seeking behaviors among the total population.

Table 2: Clinical, demographic, housing and educational characteristics of study participants

\begin{tabular}{|c|c|c|c|c|}
\hline \multirow[t]{2}{*}{ Parameters } & \multirow[b]{2}{*}{ Total $(n=400)$} & \multicolumn{2}{|c|}{ Area of residence } & \multirow[t]{2}{*}{$P$ value } \\
\hline & & $\begin{array}{l}\text { Airport-West } \\
(\mathrm{n}=200)\end{array}$ & $\begin{array}{l}\text { Kaneshie } \\
(n=200)\end{array}$ & \\
\hline Mean age (years) & $31.1 \pm 0.6$ & $31.7 \pm 0.8$ & $30.6 \pm 0.9$ & 0.389 \\
\hline MPs positive & $35(8.8 \%)$ & $11(5.5 \%)$ & $24(12.0 \%)$ & 0.033 \\
\hline \multicolumn{5}{|l|}{ Marital status } \\
\hline Single & $177(44.3 \%)$ & $81(40.5 \%)$ & $94(47.0 \%)$ & 0.226 \\
\hline \multicolumn{5}{|l|}{ Educational status } \\
\hline Illiterate & $35(8.8 \%)$ & $0(0.0 \%)$ & $35(17.5 \%)$ & $\mathrm{P}<0.0001$ \\
\hline Basic & $33(8.25 \%)$ & $8(4.0 \%)$ & $25(12.5 \%)$ & 0.003 \\
\hline Secondary & $105(26.3 \%)$ & $34(17.0 \%)$ & $71(35.5 \%)$ & $\mathrm{P}<0.0001$ \\
\hline Tertiary & $227(56.8 \%)$ & $158(79.0 \%)$ & $69(34.5 \%)$ & $\mathrm{P}<0.0001$ \\
\hline \multicolumn{5}{|l|}{ Employment status } \\
\hline Formally employed & $127(31.8 \%)$ & $85(42.5 \%)$ & $42(21.0 \%)$ & $\mathrm{P}<0.0001$ \\
\hline Self-employed & $150(37.5 \%)$ & $54(27.0 \%)$ & $96(48.0 \%)$ & $\mathrm{P}<0.0001$ \\
\hline Unemployed & $123(30.8 \%)$ & $61(30.5 \%)$ & $62(31.0 \%)$ & 1.000 \\
\hline \multicolumn{5}{|l|}{ Nature of housing } \\
\hline Excellent & $39(9.7 \%)$ & $39(19.5 \%)$ & $0(0.0 \%)$ & $\mathrm{P}<0.0001$ \\
\hline Very good & $167(41.8 \%)$ & $130(65.0 \%)$ & $37(18.5 \%)$ & $\mathrm{P}<0.0001$ \\
\hline Good & $137(34.3 \%)$ & $31(15.5 \%)$ & $106(53.0 \%)$ & ) $\quad \mathrm{P}<0.0001$ \\
\hline Poor & $57(14.3 \%)$ & $0(0.0 \%)$ & $57(28.5 \%)$ & $\mathrm{P}<0.0001$ \\
\hline $\begin{array}{l}\text { Number of people } \\
\text { in homes }\end{array}$ & $4.5 \pm 0.1$ & $3.7 \pm 0.1$ & $5.2 \pm 0.2$ & $\mathrm{P}<0.0001$ \\
\hline
\end{tabular}

$\mathrm{MP}=$ malaria parasite; Nature of housing $=$ Coded description of housing 
Malaria knowledge, health-seeking behavior and control mechanisms

In table 3, knowledge about malaria, health seeking behavior and control mechanisms employed by the participants are shown. Residents of Kaneshie had a much lower level of knowledge about malaria than those of Airport West. Though self-medication was widespread in both communities, it was more common among the residents of Kaneshie (81.5\%: p=0.004) compared to those from Airport West (68.5\%). Conventional choice of treatment was preferred over herbal forms among Airport West residents (96.5\%: $\mathrm{p}<0.0001)$ than in Kaneshie (80.5\%). Participants who preferred both forms of treatment were more in
Kaneshie $(14.5 \%$ : $\mathrm{p}<0.0001)$ than in Airport West $(2.0 \%)$. The people in Airport West completed their treatment courses $(69.0 \%$ : $\mathrm{p}<0.0001)$ during malaria episodes when compared to those in Kaneshie (13.5\%). The cost of treatment for a single episode of malaria was averagely higher among Airport West residents (25.67 GH $\mu$ : p=0.0004), Kaneshie $(8.82 \mathrm{GH} \mu)$. Inhabitants of Airport West $(60.5 \%: \mathrm{p}<0.0001)$ preferred insecticide sprays as a vector control mechanism whereas those in Kaneshie $(21.0 \%$ : $\mathrm{p}<0.0001)$ preferred the use of mosquito coils. Most people in Kaneshie (40.0\%: $\mathrm{p}=0.004)$ did not use any form of malaria control mechanism.

Table 3: Malaria knowledge, health-seeking behaviour, choice of drugs and control mechanisms among study participants

\begin{tabular}{|c|c|c|c|c|}
\hline \multirow[t]{2}{*}{ Parameters } & \multirow[b]{2}{*}{ Total $(n=400)$} & \multicolumn{2}{|c|}{ Area of Residence } & \multirow[b]{2}{*}{$\mathbf{P}$ value } \\
\hline & & $\begin{array}{l}\text { Airport-West } \\
(\mathrm{n}=200)\end{array}$ & $\begin{array}{l}\text { Kaneshie } \\
(n=200)\end{array}$ & \\
\hline \multicolumn{5}{|l|}{ Malaria knowledge } \\
\hline Very good & $196(49.0 \%)$ & $134(67.0 \%)$ & $62(31.0 \%)$ & $\mathrm{P}<0.0001$ \\
\hline Good & $168(42.0 \%)$ & $64(32.0 \%)$ & $104(52.0 \%)$ & $\mathrm{P}<0.0001$ \\
\hline Poor & $36(9.0 \%)$ & $2(1.0 \%)$ & $34(17.0 \%)$ & $\mathrm{P}<0.0001$ \\
\hline \multicolumn{5}{|c|}{ Health-seeking behavior } \\
\hline Hospital/Clinic & $76(19.0 \%)$ & $47(23.5 \%)$ & $30(15.0 \%)$ & 0.042 \\
\hline Self-medication & $300(75.0 \%)$ & $137(68.5 \%)$ & $163(81.5 \%)$ & 0.004 \\
\hline None & $24(6.0 \%)$ & $17(8.5 \%)$ & $7(3.5 \%)$ & 0.056 \\
\hline \multicolumn{5}{|l|}{ Drug of choice } \\
\hline Conventional & $354(88.5 \%)$ & $193(96.5 \%)$ & $161(80.5 \%)$ & $\mathrm{P}<0.0001$ \\
\hline Herbal & $13(3.25 \%)$ & $3(1.5 \%)$ & $10(5.0 \%)$ & 0.087 \\
\hline Both & $33(8.25 \%)$ & $4(2.0 \%)$ & $29(14.5 \%)$ & $\mathrm{P}<0.0001$ \\
\hline Drug stock & $120(30.0 \%)$ & $61(30.5 \%)$ & $59(29.5 \%)$ & 0.913 \\
\hline Course completion & $165(41.3 \%)$ & $138(69.0 \%)$ & $27(13.5 \%)$ & $\mathrm{P}<0.0001$ \\
\hline Prophylactic use & $59(14.8 \%)$ & $31(15.5 \%)$ & $28(14.0 \%)$ & 0.778 \\
\hline Treatment cost $(\mathrm{GH} \mu)$ & $22.81 \pm 1.84$ & $25.67 \pm 2.08$ & $8.82 \pm 0.88$ & 0.0004 \\
\hline \multicolumn{5}{|l|}{ Control mechanisms } \\
\hline Insecticide spray & $182(45.5 \%)$ & $121(60.5 \%)$ & $61(30.5 \%)$ & $\mathrm{P}<0.0001$ \\
\hline ITN'S & $41(10.3 \%)$ & $25(12.5 \%)$ & $16(8.0 \%)$ & 0.1867 \\
\hline Repellant creams & $3(0.8 \%)$ & $2(1.0 \%)$ & $1(0.5 \%)$ & 1.000 \\
\hline Coils & $42(10.5 \%)$ & $0(0.0 \%)$ & $42(21.0 \%)$ & $\mathrm{P}<0.0001$ \\
\hline None & $132(33.0 \%)$ & $52(26.0 \%)$ & $80(40.0 \%)$ & 0.004 \\
\hline
\end{tabular}

ITN's=Insecticide treated nets; $-\mathrm{GH} \mu=$ Ghana cedi

\section{Demography, Knowledge, health seeking behavior and control mechanisms (Malaria Infected Individuals)}

Table 4 represents the characteristics of malariainfected participants $(n=35)$ stratified by area of residence. More females in Kaneshie (70.8\%: $\mathrm{p}=0.015)$ were infected compared to females in Airport West (54.5\%). Infected participants in African Health Sciences Vol 13 Issue 4 December 2013
Kaneshie were mostly unemployed (50.0\%: $\mathrm{p}=0.014)$. Kaneshie residents who used Insecticide Treated Nets (ITN's) $(16.7 \%$ : $\mathrm{p}=0.008)$ had a higher frequency of infection than those in Airport West $(0.0 \%)$ who used the same control method. There was no significant difference in educational status, drug stock and the use of prophylactics among the population. 
Table 4: General characteristics of malaria infected participants stratified by area of residence

\begin{tabular}{|c|c|c|c|}
\hline \multirow[t]{2}{*}{$\overline{\text { Parameters }}$} & \multicolumn{2}{|c|}{ Area of residence } & \multirow[b]{2}{*}{$\mathrm{p}$ value } \\
\hline & $\begin{array}{l}\text { Airport West } \\
(n=11)\end{array}$ & $\begin{array}{l}\text { Kaneshie } \\
(n=24)\end{array}$ & \\
\hline \multicolumn{4}{|l|}{$\overline{\text { Sex }}$} \\
\hline Male & $5(45.5 \%)$ & $7(29.2 \%)$ & 0.5634 \\
\hline Female & $6(54.5 \%)$ & $17(70.8 \%)$ & 0.0149 \\
\hline Number of people in home & $4.18 \pm 0.46$ & $4.63 \pm 0.47$ & 0.5658 \\
\hline \multicolumn{4}{|l|}{ Educational status } \\
\hline Tertiary & $7(63.6 \%)$ & $2(8.3 \%)$ & 0.5864 \\
\hline Secondary & $3(27.3 \%)$ & $7(29.2 \%)$ & 0.8657 \\
\hline Basic & $1(9.0 \%)$ & $7(29.2 \%)$ & 0.3732 \\
\hline Illiterate & $0(0.0 \%)$ & $8(33.3 \%)$ & \\
\hline \multicolumn{4}{|l|}{ Employment status } \\
\hline Formally employed & $4(36.4 \%)$ & $0(0.0 \%)$ & 0.1531 \\
\hline Self employed & $4(36.4 \%)$ & $12(50.0 \%)$ & 0.3321 \\
\hline Unemployed & $3(27.3 \%)$ & $12(50.0 \%)$ & 0.0144 \\
\hline Nature of housing & $4(36.4 \%)$ & $0(0.0 \%)$ & “ \\
\hline \multicolumn{4}{|l|}{ Excellent } \\
\hline Very good & $5(45.5 \%)$ & $2(8.3 \%)$ & 0.8941 \\
\hline Good & $2(18.2 \%)$ & $14(58.3 \%)$ & 0.2961 \\
\hline Poor & $0(0.0 \%)$ & $8(33.3 \%)$ & \\
\hline \multicolumn{4}{|l|}{ Knowledge about malaria } \\
\hline Very good & $5(45.5 \%)$ & $6(25.0 \%)$ & 0.0926 \\
\hline Good & $6(54.5 \%)$ & $13(54.2 \%)$ & 0.5346 \\
\hline Poor & $0(0.0 \%)$ & $5(20.8 \%)$ & 0.5589 \\
\hline Drug stock & $3(27.3 \%)$ & $7(29.2 \%)$ & 0.1687 \\
\hline Course completion & $8(72.7 \%)$ & $2(8.3 \%)$ & 0.7484 \\
\hline Prophylactic use & $0(0.0 \%)$ & $1(4.2 \%)$ & 0.2886 \\
\hline \multicolumn{4}{|l|}{ Control mechanisms } \\
\hline Insecticide spray & $8(72.7 \%)$ & $3(12.5 \%)$ & 0.6509 \\
\hline Insecticide treated nets & $0(0.0 \%)$ & $4(16.7 \%)$ & 0.0085 \\
\hline Repellant creams & $0(0.0 \%)$ & $0(0.0 \%)$ & “ \\
\hline Coils & $0(0.0 \%)$ & $6(25.0 \%)$ & “ \\
\hline None & $3(27.3 \%)$ & $11(45.8 \%)$ & 0.233 \\
\hline
\end{tabular}

\section{Discussion}

This study sought to determine the most important factors that may affect malaria prevalence in two communities within an urban area. The overall prevalence of malaria from both sites was $8.75 \%$, which was generally low. The prevalence from the individual sites took the same trend. This is contrary to a study conducted in Benin City, Nigeria which reported a total prevalence rate of $168(34.2 \%)$ out of 491 participants $^{6}$. In that study, Akinbo and his colleagues suggested that the relatively high prevalence may be due to poor control measures. However, in countries like Togo, long-lasting insecticide treated nets have been distributed throughout the country, reducing the prevalence rate to an appreciable level ${ }^{7}$. Observations made during our study revealed similar control strategies in the homes studied. This might have contributed to the relatively lower prevalence rate recorded in this study.

The finding from the current study suggests that malaria prevalence differs even within different sections of a particular area. Crompton and Savioli (1993) observed that differences in prevalence of parasitic infections are probably an indication of differences in population densities, overcrowding and unhygienic conditions ${ }^{8}$. The differences in prevalence between the two areas sampled in our study could also be related to the local environmental factors inherent in 
each area, (for example, condition of drainage systems and overcrowding) especially at Kaneshie.

Females from both sites were more prone to malaria than males. A yet similar but contrasting study conducted in North West Burkina-Faso showed a higher prevalence in females $(23.8 \%)$ than males $(21.9 \%)$ but was not statistically significant ${ }^{9}$. The trend in the current study however contradicts a work in the Al-Tameen province, Iraq, where more males were infected than females ${ }^{10}$. The high incidence of malaria amongst females in the Kaneshie community could be due to the commercial activities (mostly trading) involving early and late outdoor staying of which more females are involved.

As shown in table 2, education at all levels was significantly lower in Kaneshie than Airport West. Given that malaria prevalence was different between the two areas, is an indication that education may have some influence on the prevalence of malaria. This observation conforms to two other studies conducted along the Thai-Myanmar border area and in Egypt. These studies established the proportion of educational levels in malaria cases to be lower than in non-malaria controls ${ }^{11,12}$. Amongst the malaria-infected individuals the unemployed were more, contributing half the number at Kaneshie. This compares to a study in Egypt where results showed that malaria infection increases with the decrease in socioeconomic level of families and among the unemployed or students ${ }^{12}$. The difference in standard of living between the two groups in our study could be an indicator of the higher cost and more effective treatment of an episode of malaria among the Airport West residents. In a study conducted in Central Vietnam the wealthiest group was much less infected with malaria $(8.9 \%)$ than the lower and medium income $(16.6 \%)$ category $^{13}$.

Self-medication was preferred among the general population, but was practiced more amongst residents of Kaneshie. Shulman ${ }^{14}$ observed that self-medication has become popular as a result of the creation of awareness through education on home management and control of malaria. During this study, we observed that people from both sites had adequate information on home management of malaria, especially through awareness programs organised through the media. However, the higher rate of selfmedication did not reduce the prevalence of malaria in Kaneshie; a situation that contradicts an observation made by Mockenhaupt and colleagues in $2000^{15}$, that antimalarial drugs are associated with fewer malaria parasite infections. This could be due to the fact that rampant self-medication is gradually leading to more drug resistant forms of the Plasmodium parasite, reducing drug effectiveness in most cases.

A greater number of Airport West residents visited the hospital more than their counterparts from Kaneshie. This could be due to differences in income levels and therefore the ability to afford effective malaria treatment. This is in agreement with an observation made by Adams and colleagues ${ }^{16}$. They suggested that poor people are at an increased risk of malaria infection and death and are also less likely to be able to pay for effective malaria treatment and/or transportation to a health facility. In the report, reference is made to a study in the Kassena-Nankana District in the Upper East Region of Ghana, where the cost of malaria care was $1 \%$ and $34 \%$ of the income of the rich and poor respectively ${ }^{16}$.

The control methods used in both sites differed greatly. This may be attributed to the difference in the standard of living in these areas. This compels most of the occupants of Kaneshie to use coils and other cheaper forms of mosquito control ${ }^{16}$.

\section{Conclusion}

Malaria prevalence differs within different communities in the same urban area. Considering the differences in prevalence, the following factors; age, education, employment, number of people in a home, health seeking behavior, compliance to treatment, control mechanism and standard of living may influence malaria prevalence. To enhance the fight against malaria new tools and techniques are still needed. There is thus need for community-centered control, community involvement and education especially in areas with low levels of education and urbanization.

\section{'Acknowledgements}

The authors are grateful to the ethics committee and the staff and management of Kaneshie polyclinic and Lister hospital for their immense contributions to making this work a success. To all participants who volunteered and consented to making the study a success, we say thank you. Gratitude also goes to Dr. Nafiu Amidu for his support and contributions.

\section{References}

1. Ministry of Health, MOH, Roll Back Malaria Strategic Plan 2001-2010. 2000: Accra.

2. Chucks J, Aboh I.K (2003) Prevalence and Management of Malaria in Ghana:A case study of the Volta Region. Volume 22, 139.

3. Keiser J, Utzinger J, Caldas de Castro M, Smith TA, Tanner M, Singer BH. Urbanization in sub- 
saharan Africa and implication for malaria control. Am J Trop Med Hyg 2004; 71(2 Suppl): 118-27.

4. Districts G, Greater Accra. 2006 [cited 2010 02/03]; Available from: http:// www.ghanadistricts.com/region.

5. Cnops L, Van Esbroeck M, Bottieau E, Jacobs J. Giemsa-stained thick blood films as a source of DNA for Plasmodium species-specific realtime PCR. Malar 2010; 9: 370.

6. Akinbo FO, Okaka CE, Omeregie R, Mordi $\mathrm{R}$, Igbinuwen $\mathrm{O}$. Prevalence of malaria and anaemia among HIV-infected patients in Benin City, Nigeria. New Zealand Journal of Medical Laboratory Science, 2009; 63(3): 78-80.

7. Eliades MJ, Wolkon A, Morgah K, Crawford SB, Dorkenoo A, Sodahlon Y, Hawley WA, et al. Burden of malaria at community level in children less than 5 years of age in Togo. $A m J$ Trop Med Hyg, 2006; 75(4): 622-9.

8. Crompton DW, Savioli L. Intestinal parasitic infections and urbanization. Bull World Health Organ 1993; 71(1): 1-7.

9. Ye Y, Hoshen M, Louis V, Seraphin S, Traore I, Sauerborn R. Housing conditions and Plasmodium falciparum infection: protective effect of iron-sheet roofed houses. Malar J 2006; 5: 8.

10. Kadir MA, Ismail AK, Tahir S.S. Epidemiology of malaria in Al-Tameem Province, Iraq, 19912000. East Mediterr Health J 2003; 9(5-6): 10427.

11. Chaveepojnkamjorn, W. and N. Pichainarong, Malaria infection among the migrant population along the Thai-Myanmar border area. Southeast Asian J Trop Med Public Health 2004; 35(1): 4852.

12. Dahesh SM, Bassiouny HK, El-Masry SA. Socioeconomic and environmental factors affecting malaria infection in Fayoum Governorate, Egypt. J Egypt Soc Parasitol 2009; 39(2): 511-23.

13. Thang ND, Erhart A, Speybroeck N, Hung le X, Thuan le K, Hung CT, Ky PV, et al. Malaria in central Vietnam: analysis of risk factors by multivariate analysis and classification tree models. Malar J 2008; 7: 28.

14. Shulman CE. Malaria in pregnancy: its relevance to safe-motherhood programmes. Ann Trop Med Parasitol, 1999; 93 Suppl 1: S59-66.

15. Mockenhaupt FP, Rong B, Till H, Eggelte TA, Beck S, Gyasi-Sarpong C, Thompson WN, Bienzle U. Submicroscopic Plasmodium falciparum infections in pregnancy in Ghana. Trop Med Int Health 2000;5(3): 167-73.

16. Adams I, Darko D, Accorsi S. Improving Efficiency: Accessing Efficiency in Health Delivery. Bulletin of Health Information 2004; 1(1): 20-27.

17. Parajuli, K. and P. Ghimire, Epidemiology of malaria in two Eastern districts of Nepal. Kathmandu Univ Med J (KUMJ) 2010; 8(29): 4550.

18. Saganuwan AS, Adelaiye P.O. The Epidermilogy of malaria in University of Agriculture Makurdi Health Centre, Makurdi, Nigeria. African Journal of Clinical and Experimental Microbiology 2007; 8(3): 122-129. 